\title{
Effects of Dietary Grape Pomace Supplementation on Performance, Carcass Traits and Meat Quality of Lambs
}

\author{
IOANNIS KAFANTARIS ${ }^{1,2}$, BASILIKI KOTSAMPASI ${ }^{2}$, VLADIMIROS CHRISTODOULOU ${ }^{2}$, \\ SOTIRIA MAKRI ${ }^{1}$, DIMITRIOS STAGOS ${ }^{1}$, KONSTANTINOS GERASOPOULOS $^{1}$, \\ KONSTANTINOS PETROTOS ${ }^{3}$, PANAGIOTIS GOULAS ${ }^{3}$ and DEMETRIOS KOURETAS ${ }^{1}$ \\ ${ }^{1}$ Department of Biochemistry and Biotechnology, University of Thessaly, Viopolis, Larissa, Greece; \\ ${ }^{2}$ Research Institute of Animal Science/Hellenic Agricultural Organization (HAO)-Demeter, Giannitsa, Greece; \\ ${ }^{3}$ Department of Biosystem Engineering, Technical Education Institute of Thessaly, Larissa, Greece
}

\begin{abstract}
Background/Aim: A previous study revealed that the inclusion of grape pomace $(G P)$ in the diet for growing lambs had beneficial effects on the redox status and fecal microbiota. Herein, we investigated the effect of GP inclusion on performance, carcass traits and fatty acid composition of meat. Materials and Methods: In the experimental trial of 55 days, lambs were fed with standard or diet supplemented with GP. Performance, carcass traits and fatty acid profile of quadriceps muscle were assessed. Results: GP inclusion in the diet improved growth performance, since the average daily gain was significantly increased by 2-fold in GP group. Regarding the fatty acid composition of meat, GP inclusion significantly increased the content of long chain n-3 fatty acids, eicosapentaenoic acid and docosahexaenoic acid, and reduced the n-6/n-3 ratio compared to the control group. Conclusion: GP supplementation in lamb diet may improve performance and may have beneficial effects on meat quality.
\end{abstract}

Apart from being an important source of protein, vitamins and dietary fiber, meat also provides fat, including saturated fatty acids (SFA), unsaturated fatty acids (UFA), cholesterol and triacylglycerol. Fatty acids in meat are vital components that contribute to the nutrient value of meat in terms of

This article is freely accessible online.

Correspondence to: Demetrios Kouretas, Department of Biochemistry and Biotechnology, University of Thessaly, Viopolis, Mezourlo, Larissa 41500, Greece. Tel: +30 2410565277, Fax: +30 2410565293, e-mail: dkouret@uth.gr

Key Words: Fatty acids, grape pomace, lambs, meat quality, polyphenols. physiological and biochemical functions. Several studies have shown that the content of fatty acids can strongly be influenced by nutrition $(1,2)$.

Sheep meat and products are widely consumed worldwide. Ruminant edible fat contains high content of SFA, poor content of health-promoting polyunsaturated fatty acids (PUFA) and variable amounts of fatty acids derived from rumen metabolism such as trans-fatty acids and conjugated fatty acids. The high saturation of edible fat has raised concerns about its contribution to the increase risk of cardiovascular diseases and metabolic syndrome. Thus, manipulation of fatty acid composition of meat in order to reduce SFA content and the $n-6 / n-3$ ratio, and increase the PUFA content is a major target in the field of ruminant research (3).

Recently, researchers have demonstrated the possibility of developing meat products with potential health benefits by introducing bioactive compounds with antioxidant properties into feedstuffs for animals $(4,5)$. Our research group has also performed in vivo studies showing that by-products rich in polyphenols, generated from olive oil and the wine industry, improved antioxidant capacity, meat quality and welfare of productive animals, such as chickens, pigs and lambs (6-13).

In the field of animal nutrition, plant extracts rich in polyphenols have been extensively studied as potential sources of natural antioxidants to replace their synthetic counterparts. The valorization of by-products, such as those of the wine industry, is of important interest since their use in animal nutrition may provide benefits in animal health, productivity and meat quality. At the same time, the extensive use of winery by-products in feedstuffs for productive animals may have beneficial effects on the environment by reducing the risk of phytotoxic phenomena from their deposition on soil (14). 
Grape pomace (GP) is a by-product from wine production and refers to the solid remains following pressing of grapes for juice. It contains high levels of polyphenols and dietary fiber (15). GP exhibits important antioxidant and antibacterial properties (16). Furthermore, the use of GP in animal feed not only prevents oxidation, but also improves meat quality (17).

It is well established that meat quality refers to the attractiveness of meat to consumers. As mentioned above, meat quality can be influenced principally by the animal's nutrition, through its effects on the amount and type of fat in meat. In recent years, interest in meat fatty acid composition has stemmed mainly from the need to find nutritional strategies to produce healthier meat, i.e. meat with a higher ratio of PUFA to SFA and a lower $n-6 / n-3$ ratio. In particular, the $n-6 / n-3$ ratio in meat has become of important significance in human nutrition, since consumption of meat enriched with long chain n-3 fatty acids, such as eicosapentaenoic acid (EPA) and docosahexaenoic acid (DHA), is beneficial. The main benefits associated with EPA and DHA are their anti-inflammatory properties (18), cardiovascular protective effects (19) and reduction of the risks for specific types of cancer (20).

In a previous study, we showed that GP inclusion in the diet of lambs had beneficial effects on the redox status and fecal microbiota of growing lambs $(9,11)$. In extension of this, the objective of this study was to evaluate GP supplementation in diets for growing lambs relative to growth performance, carcass traits and fatty acid composition of meat.

\section{Materials and Methods}

Winery by-product and silage preparation. GP from red grapes (Vitis vinifera L. var. Moschato) was obtained from a winery in Tyrnavos (Larissa, Greece). Immediately after its production, GP was stored and processed under the common practice of ensilage. Silage was prepared as described previously (9).

Experimental design, animals, management and diets. Twenty-four male lambs of Chios breed were selected from the flock of the Research Institute of Animal Science/Hellenic Agricultural Organization - Demeter (Giannitsa, Greece). At the commencement of the study, lambs were 15 days old and weighed on average $7.99 \pm 1.80 \mathrm{~kg}$ and were divided into two homogeneous groups according to their body weight. For 27 days (15 to 42 days of age), the control group $(n=12)$ was fed with standard ration, while the GP group $(n=12)$ was fed with ration containing silage with polyphenolic additives from GP. Until the age of weaning (42 days of age), lambs remained in two separate stalls (one for each group) along with their mothers to allow suckling. Each stall was equipped with similar troughs for feeding and the lambs had free access to the rations (either to standard or to experimental ration), alfalfa hay and water for consumption ad libitum. The ewes were fed with standard ration without having access to the rations of lambs. After weaning, lambs were separated from their mothers and the two groups of lambs were fed with their respective diet and alfalfa hay for 28 days (i.e. from 42 to 70 days of age) until the end of the experiment. The diets for lambs were formulated according to the National Research Council (21) and the chemical composition was determined according to methods of the Association of Official Analytical Chemists (22) (Table I). The net energy (NE) content of the diets was estimated by the equations of Van Es (23). The experiment was reviewed and approved by the Institutional Review Board of the University of Thessaly (no. 89/10.12.2014). All lambs used in this study were cared for in accordance with the Guide for the Care and Use of Laboratory Animals (24).

During the 55-day experimental trial, lambs were weighed individually weekly and average daily gain (ADG, g/day) was calculated. At 42 and at 70 days of age, six lambs of each group were fasted for $18 \mathrm{~h}$ (water was allowed ad libitum), weighed and slaughtered. Additionally, fasting body weight, cold carcass weight, carcass yield and carcass traits were assessed. At 70 days of age, the intramuscular fatty acid profile of quadriceps muscle was also assessed. All relevant procedures (e.g. slaughter, bleeding, skin removal, gutting, viscera separation and washing) were executed by specialized personnel. In a previous study, the effect of GP inclusion on lipid peroxidation and protein oxidation was also assessed. Specifically, at 42 and 70 days of age, oxidative stress biomarkers including thiobarbituric acid-reactive substances (TBARS) and protein carbonyls were measured in quadriceps muscle in order to evaluate the effect of GP inclusion on meat oxidation (9).

Carcass assessment, yield and traits. After dressing and storing for $24 \mathrm{~h}$ at $3^{\circ} \mathrm{C}$ carcasses were weighed according to European Economic Community (EEC) guidelines (25). To assess carcass traits, a 10-point scale was used according to Christodoulou et al. (26). The following carcass traits were assessed: lean color (' 1 ', being most red and ' 10 ' being most pink), fat color (' 1 ' being most yellow and ' 10 ' being most white), fat firmness (' 1 ' being most oily and ' 10 ' being most firm), carcass wetness (' 1 ' being most wet and ' 10 ' being least wet) and overall acceptability (' 1 ' being least acceptable and ' 10 ' being most acceptable).

Sample preparation and fatty acid methyl ester (FAME) synthesis. At 70 days of age, after slaughter, tissues of quadriceps muscle were quickly removed and snap-frozen in liquid nitrogen. The homogenization of tissues was performed as described previously (7). Briefly, one part of tissue powder was homogenized with two parts (weight/volume) of $0.01 \mathrm{M}$ phosphate-buffered saline $\mathrm{pH} 7.4$ (138 mM NaCl, $2.7 \mathrm{mM} \mathrm{KCl}$, and $1 \mathrm{mM}$ EDTA) and a protease inhibitor tablet (Complete ${ }^{\mathrm{TM}}$ mini protease inhibitors; Roche, Munich, Germany) was added. The homogenate was then vortexed, briefly sonicated on ice and then centrifuged at $12,000 \times g$ for $30 \mathrm{~min}$ at $4^{\circ} \mathrm{C}$ and the supernatant was collected. The homogenized tissues were then stored at $-80^{\circ} \mathrm{C}$ until fatty acid conversion to FAME for subsequent analysis.

The method of FAME synthesis was applied according to Gerasopoulos et al. (8). Briefly, to $0.5 \mathrm{ml}$ of homogenized tissue, $1 \mathrm{ml}$ methanolic solution of $600 \mu \mathrm{g} / \mathrm{ml}$ tridecanoid acid (13:0) was added as an internal standard. Subsequently, $0.4 \mathrm{ml}$ of $10 \mathrm{~N} \mathrm{KOH}$ and $2.7 \mathrm{ml}$ of pure methanol were added. For proper hydrolysis of samples, the tubes were placed in a water-bath at $55^{\circ} \mathrm{C}$ for $1.5 \mathrm{~h}$ with vigorous stirring every $20 \mathrm{~min}$. Cooling with tap water was followed for $15 \mathrm{~min}$. Then, $0.3 \mathrm{ml}$ of $24 \mathrm{~N} \mathrm{H}_{2} \mathrm{SO}_{4}$ was added and the tubes were placed in a water-bath at $55^{\circ} \mathrm{C}$ for $1.5 \mathrm{~h}$, with vigorous stirring every $20 \mathrm{~min}$. Subsequently, the samples were 
Table I. Ingredient composition $(\% \mathrm{w} / \mathrm{w})$ and nutrient content $[\mathrm{g} / \mathrm{kg} \mathrm{dry}$ matter (DM)] of the diets given before and after Iamb weaning.

\begin{tabular}{|c|c|c|c|c|}
\hline \multirow[b]{2}{*}{ Ingredient } & \multicolumn{2}{|c|}{ Before weaning } & \multicolumn{2}{|c|}{ After weaning } \\
\hline & Control & GP & Control & GP \\
\hline Corn silage $^{a}$ & 45.0 & 45.0 & 45.0 & 45.0 \\
\hline Wheat bran & 9.0 & 9.0 & 15.0 & 15.0 \\
\hline Wheat grain & 0 & 0 & 13.0 & 13.0 \\
\hline Sunflower meal & 0 & 0 & 4.0 & 4.0 \\
\hline Soybean meal $44 \%$ & 21.0 & 21.0 & 18.0 & 18.0 \\
\hline Milk replacer & 20.0 & 20.0 & 0 & 0 \\
\hline Vitamin and mineral premix $(2.5 \%)$ & 2.5 & 2.5 & 2.5 & 2.5 \\
\hline Salt & 0.5 & 0.5 & 0.5 & 0.5 \\
\hline Limestone & 1.2 & 1.2 & 1.2 & 1.2 \\
\hline Monocalcium phosphate & 0.8 & 0.8 & 0.8 & 0.8 \\
\hline \multicolumn{5}{|l|}{ Chemical composition ${ }^{\mathrm{b}}$ (g/kg DM) } \\
\hline Net energy for gainc $(\mathrm{MJ} / \mathrm{kg} \mathrm{DM})$ & 4.85 & 5.30 & 5.01 & 5.45 \\
\hline Dry matter & 902 & 936 & 883 & 917 \\
\hline Crude protein & 183 & 184 & 168 & 169 \\
\hline Crude fat & 57.7 & 60.0 & 29.9 & 32.1 \\
\hline Crude fiber & 35.7 & 62.3 & 50.1 & 76.6 \\
\hline Ash & 43.3 & 46.0 & 30.1 & 32.8 \\
\hline Calcium & 12.9 & 13.8 & 13.1 & 14.0 \\
\hline Phosphorus & 6.27 & 6.04 & 7.46 & 7.24 \\
\hline
\end{tabular}

Control: Standard diet; GP: diet supplemented with grape pomace. asilage contained $60 \%$ corn solids and $40 \%$ water in the control diet, and $51 \%$ corn solids, $9 \%$ grape pomace and $40 \%$ water in the GP diet. bDiets were analyzed according to the Association of Official Analytical Chemists (22). ${ }^{\mathrm{c} C a l c u l a t e d}$ from equations of Van Es (23).

cooled with water for $15 \mathrm{~min}$. Finally, $3 \mathrm{ml}$ of hexane was added as solvent and the samples were vortexed for 3 min and centrifuged at $6,000 \times g$, for $15 \mathrm{~min}$ at room temperature. The supernatant was placed in gas chromatography (GC) vials of $2 \mathrm{ml}$ and stored at $-20^{\circ} \mathrm{C}$ until $\mathrm{GC} /$ mass spectrometric (MS) analysis.

Quantification of FAME. The intramuscular fatty acid profile in quadriceps muscle of lambs was determined according to Gerasopoulos et al. (8). Fatty acids were identified using FAME standards supplied by Supelco (Bellefonte, PA, USA): 37 Component FAME Mix (product number 47885-U) and PUFA 2 (product number 47015-U). To identify the various esters of lipid oxides, MS recognition/identification of peaks in conjunction with spectral data available from the National Institute of Standards and Technology was used. Varian CP-3800 GC-MS chromatography apparatus (Varian Inc, Palo Alto, CA, USA) and an Agilent J\&W 112-88A7:100 m×0.25 $\mathrm{mm} \times 0.25 \mu \mathrm{m}$ silica column (Agilent, Frankfurt, Germany) were used. The data on fatty acid composition were processed to compute the sum of SFA, monounsaturated fatty acids, and PUFA. Fatty acids were expressed as $\mathrm{g} / 100 \mathrm{~g}$ of total FAME.

Statistical analysis. Growth performance, carcass traits and intramuscular fatty acid composition were analyzed by one-way ANOVA. The level of statistical significance was set at $p<0.05$. All results are expressed as mean \pm SEM. Data were analyzed using SPSS, version 22.0 (IBM Corp., Armonk, NY, USA).

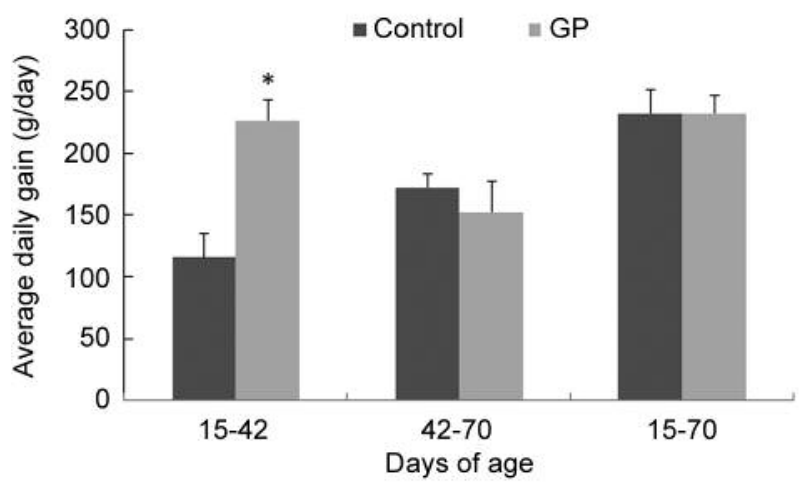

Figure 1. Average daily gain $(A D G)$ in growing lambs fed with diet supplemented with grape pomace $(G P)$. *Significantly different from the control group $(p<0.05)$. Data are expressed as the mean \pm SEM.

\section{Results}

Growth performance. Inclusion of GP in lamb diet improved performance during the experimental trial. In particular, before the weaning period (i.e. from 15 to 42 days of age), ADG was increased significantly by 2 -fold in the GP group compared to the control group. However, after weaning and considering overall period, ADG was not affected by GP inclusion in the diet (Figure 1).

Carcass yield and traits. Fasting body weight, cold carcass weight, carcass yield and carcass traits are presented in Table II. At 42 days of age, fasted body weight and cold carcass weight were increased significantly in the GP group compared with the control group. Furthermore, carcasses traits, such as fat firmness and overall acceptability were affected by the experimental diet supplemented with GP. At 70 days of age, lean color, fat firmness, carcass wetness and overall acceptability were not affected by GP inclusion in the diet. In contrast, fat color of the carcasses was significantly lower in the GP group compared to the control.

Assessment of fatty acids in lamb meat. The effect of GP inclusion in the diet on the fatty acid composition of lamb meat is summarized in Table III. Dietary GP supplementation led to significantly higher content of arachidic acid (20:0), eicosadienoic acid (cis-11, 14, 20:2n-6), EPA (20:5n-3) and DHA (22:6n-3), compared to the control group. Moreover, the meat from the GP group exhibited significantly higher content of n-3 fatty acids and significantly lower n-6/n-3 ratio compared to the control group.

\section{Discussion}

Growth performance. In livestock production, numerous factors can induce oxidative stress damage to cellular 
Table II. Fasting body weight (BW), cold carcass weight, carcass yield and traits of growing lambs.

\begin{tabular}{|c|c|c|c|}
\hline & \multicolumn{2}{|c|}{ Group } & \multirow[b]{2}{*}{$p$-Value } \\
\hline & Control & GP & \\
\hline \multicolumn{4}{|l|}{ Before weaning ( 15 to 42 days) } \\
\hline Fasted BW $(\mathrm{kg})$ & $10.16 \pm 1.06$ & $14.08 \pm 1.20 *$ & $* 0.034$ \\
\hline Cold carcass weight ${ }^{\mathrm{a}}(\mathrm{kg})$ & $5.08 \pm 0.52$ & $7.25 \pm 0.62 *$ & $* 0.023$ \\
\hline Carcass yield $(\mathrm{kg} / 100 \mathrm{~kg}$ of $\mathrm{BW})$ & $50.03 \pm 0.99$ & $51.46 \pm 0.65$ & 0.261 \\
\hline \multicolumn{4}{|l|}{ Carcass traits } \\
\hline Lean color & $8.21 \pm 0.08$ & $8.43 \pm 0.07$ & 0.091 \\
\hline Fat color & $8.30 \pm 0.05$ & $8.50 \pm 0.09$ & 0.155 \\
\hline Fat firmness & $8.23 \pm 0.04$ & $8.43 \pm 0.06^{*}$ & $* 0.034$ \\
\hline Carcass wetness & $8.41 \pm 0.06$ & $8.51 \pm 0.06$ & 0.443 \\
\hline Overall acceptability & $8.65 \pm 0.04$ & $8.83 \pm 0.05^{*}$ & $* 0.022$ \\
\hline \multicolumn{4}{|l|}{ After weaning (42 to 70 days) } \\
\hline Fasted BW (kg) & $19.16 \pm 1.24$ & $19.58 \pm 0.75$ & 0.785 \\
\hline Cold carcass weight $(\mathrm{kg})$ & $9.96 \pm 0.66$ & $10.33 \pm 0.41$ & 0.662 \\
\hline Carcass yield $(\mathrm{kg} / 100 \mathrm{~kg}$ of $\mathrm{BW})$ & $52.03 \pm 0.58$ & $52.78 \pm 0.46$ & 0.347 \\
\hline \multicolumn{4}{|l|}{ Carcass traits* } \\
\hline Lean color & $7.81 \pm 0.16$ & $7.50 \pm 0.34$ & 0.401 \\
\hline Fat color & $8.10 \pm 0.16$ & $7.33 \pm 0.21 *$ & $* 0.011$ \\
\hline Fat firmness & $7.63 \pm 0.21$ & $8.12 \pm 0.16$ & 0.095 \\
\hline Carcass wetness & $7.91 \pm 0.06$ & $7.94 \pm 0.05$ & 0.601 \\
\hline Overall acceptability & $7.94 \pm 0.04$ & $7.91 \pm 0.06$ & 0.344 \\
\hline
\end{tabular}

Control group: Standard diet; GP group: diet supplemented with grape pomace. Lambs/group=12. At 42 and 70 days of age, six lambs were slaughter from each group. aAccording to (25). *Score of 1-10 according to Christodoulou et al. (26). Bold values indicate statistically significant differences compared to the control group $(p<0.05)$.

antioxidant defense. Oxidative stress causes increased production of reactive oxygen species (ROS) and can result in suboptimal health conditions of livestock and a reduction in production efficiency (27). In the present study, growth performance was increased by GP inclusion in lamb diet. ROS induce detrimental oxidative modifications of biomolecules, causing numerous impairments to intestinal membrane integrity (28). Thus, the beneficial effects of GP on growth performance may be due to its antioxidant properties by ROS scavenging, by reducing intestinal membrane damage, and consequently by improving gut functionality. Interestingly, a previous study of our group showed that GP supplementation of the diet reduced pathogenic microorganisms and increased probiotic bacteria in lambs (9). The inclusion of GP silage as a fermented product may be also an important factor in increased growth performance, since fermentable fiber in the diet stimulates microbial fermentation in the gut, and lactic acid- and fermentation-derived volatile fatty acids, are capable of inhibiting some intestinal pathogens e.g. Escherichia coli and Salmonella spp. (29). Other studies have shown that winery by-products such as grape seed extract and GP concentrate
Table III. Intramuscular fatty acid composition in quadriceps of lambs.

\begin{tabular}{|c|c|c|c|}
\hline \multirow{2}{*}{$\begin{array}{l}\text { Fatty acid }(\mathrm{g} / 100 \mathrm{~g} \text { of } \\
\text { total fatty acids) }\end{array}$} & \multicolumn{2}{|c|}{ Group } & \multirow[b]{2}{*}{$p$-Value } \\
\hline & Control & GP & \\
\hline 10:0 & $0.23 \pm 0.03$ & $0.23 \pm 0.04$ & 0.951 \\
\hline $12: 0$ & $0.60 \pm 0.10$ & $0.66 \pm 0.11$ & 0.683 \\
\hline 14:0 & $4.12 \pm 0.60$ & $5.21 \pm 0.73$ & 0.276 \\
\hline $14: 1$ cis -9 & $0.21 \pm 0.02$ & $0.28 \pm 0.05$ & 0.292 \\
\hline $15: 0$ & $0.46 \pm 0.04$ & $0.44 \pm 0.04$ & 0.691 \\
\hline $16: 0$ & $19.48 \pm 0.97$ & $21.00 \pm 1.09$ & 0.324 \\
\hline 16:1 trans -9 & $0.45 \pm 0.02$ & $0.48 \pm 0.03$ & 0.415 \\
\hline $16: 1$ cis-9 & $1.64 \pm 0.14$ & $1.93 \pm 0.22$ & 0.292 \\
\hline $17: 0$ & $0.81 \pm 0.04$ & $0.72 \pm 0.03$ & 0.100 \\
\hline $17: 1$ cis-10 & $0.53 \pm 0.05$ & $0.55 \pm 0.05$ & 0.761 \\
\hline $18: 0$ & $13.08 \pm 0.41$ & $11.93 \pm 0.79$ & 0.222 \\
\hline 18:1 trans -9 & $0.03 \pm 0.01$ & $0.02 \pm 0.01$ & 0.862 \\
\hline 18:1 cis -9 & $29.85 \pm 1.73$ & $32.33 \pm 1.56$ & 0.313 \\
\hline $18: 1$ & $1.67 \pm 0.08$ & $1.39 \pm 0.14$ & 0.126 \\
\hline $18: 2$ trans $-9,12 \mathrm{n}-6$ & $0.24 \pm 0.03$ & $0.24 \pm 0.02$ & 0.931 \\
\hline $18: 2$ cis- 9,12 n-6 & $10.93 \pm 1.03$ & $9.47 \pm 0.95$ & 0.320 \\
\hline $18: 3$ cis- $6,9,12$ n-6 & $0.12 \pm 0.02$ & $0.12 \pm 0.01$ & 0.924 \\
\hline $18: 3$ n-3 (ALA) & $0.87 \pm 0.06$ & $0.72 \pm 0.07$ & 0.135 \\
\hline $20: 0$ & $0.04 \pm 0.02$ & $0.09 \pm 0.01 *$ & 0.038 \\
\hline $20: 1$ cis-11 & $0.11 \pm 0.02$ & $0.16 \pm 0.01$ & 0.097 \\
\hline $20: 2$ cis $-11,14$ n-6 & $0.03 \pm 0.02$ & $0.11 \pm 0.02 *$ & 0.009 \\
\hline $21: 0$ & $0.25 \pm 0.04$ & $0.22 \pm 0.05$ & 0.682 \\
\hline $20: 4$ cis- $5,8,11,14 \mathrm{n}-6$ & $5.10 \pm 0.71$ & $3.77 \pm 0.69$ & 0.212 \\
\hline $20: 5$ n-3 (EPA) & $0.45 \pm 0.04$ & $0.67 \pm 0.05^{*}$ & 0.007 \\
\hline $22: 6$ n-3 (DHA) & $0.42 \pm 0.07$ & $0.79 \pm 0.05^{*}$ & 0.001 \\
\hline $24: 1$ cis-15 & $0.17 \pm 0.03$ & $0.19 \pm 0.03$ & 0.663 \\
\hline Other ${ }^{\mathrm{a}}$ & $8.14 \pm 1.13$ & $6.31 \pm 1.20$ & 0.291 \\
\hline Sum of n-6 PUFA & $16.41 \pm 1.71$ & $13.71 \pm 1.56$ & 0.272 \\
\hline Sum of n-3 PUFA & $1.74 \pm 0.16$ & $2.17 \pm 0.08^{*}$ & 0.036 \\
\hline$n-6 / n-3$ ratio & $9.43 \pm 0.54$ & $6.28 \pm 0.64 *$ & 0.004 \\
\hline SFA & $39.06 \pm 1.50$ & $40.49 \pm 1.18$ & 0.476 \\
\hline MUFA & $34.93 \pm 1.84$ & $37.50 \pm 1.71$ & 0.334 \\
\hline PUFA & $18.73 \pm 1.79$ & $16.39 \pm 1.55$ & 0.371 \\
\hline PUFA/SFA & $0.49 \pm 0.07$ & $0.41 \pm 0.05$ & 0.387 \\
\hline (MUFA+PUFA)/SFA & $1.39 \pm 0.07$ & $1.34 \pm 0.05$ & 0.603 \\
\hline
\end{tabular}

ALA: $\alpha$-Linolenic acid; DHA: docohexaenoic acid; EPA: eicosapentaenoic acid; GP: grape pomace; MUFA: total monounsaturated acids; PUFA: total polyunsaturated fatty acids; SFA: total saturated fatty acids. Control group: Standard diet; GP group: diet supplemented with grape pomace. Lambs/group $=6$. Meat samples were collected at 70 days of age. aRepresents other known and unidentified fatty acids. Bold values indicate statistically significant differences compared to the control group $(p<0.05)$.

did not affect performance in chickens (30.31). The present results suggest that GP could be included in the diet of growing lambs with considerable economic effects for animal breeders and agricultural economy.

Fatty acid composition and meat quality. It is well established that meat fatty acid composition has a great impact on meat quality and human health (32). 
Consequently, in recent years, there has been an increased interest in strategies to manipulate the fatty acid composition of meat in productive animals through nutrition. Fatty acid profile analysis of both groups in this study revealed that among all fatty acids detected, oleic (cis-9, 18:1) and palmitic (16:0) contents were the highest. Palmitic and oleic acids are the predominant fatty acids in subcutaneous fat and in muscles (33). Furthermore, in the present study, GP supplementation affected the long-chain n-3 fatty acids and consequently the $n-6 / n-3$ ratio. In particular, the inclusion of GP in the diet significantly increased the content of EPA and DHA. Since PUFAs are important for human nutrition and health (34), their increase in lamb meat reveals the beneficial effect of inclusion of GP in the animals' diet on meat quality. The long-chain docosapentaenoic acid (22:5n3) was not detected in meat samples, although it was included in the standard FAME mixture that was used for FAME analysis. Regarding the $n-6 / n-3$ ratio, the supplementation of winery by-product had beneficial effect on meat quality since n-6/n-3 ratio was significantly lower in GP group, compared to control group. This result may be mainly due to the increased content of EPA and DHA n-3 fatty acids. The fact that GP supplementation significantly reduced the $n-6 / n-3$ ratio is of special interest since several studies have stressed the beneficial effects of consumption of meat characterized by a lower $n-6 / n-3$ ratio on human health (35-37).

Our group previously demonstrated that GP inclusion in the diets of lambs did not significantly affect protein oxidation and lipid peroxidation in quadriceps muscle (9). However, at 42 and 70 days of age, a slight decrease in TBARS and protein carbonyls was observed. In another study by our research group, we also reported that diet enriched in polyphenols from GP reduced the $n-6 / n-3$ ratio and improved the meat fatty acid profile in growing piglets (13). In a recent study, Muíño et al. (38) showed that inclusion of another winery by-product (red wine extract) in the diet also reduced the $n-6 / n-3$ ratio of lamb meat.

In conclusion, from the present study it is evident that the valorization of winery by-product by its inclusion in the diet of growing lambs improved growth performance by increasing body weight and showed a significantly beneficial effect on meat quality by enriching meat with n3 PUFA. Consequently, GP could be included in feedstuffs with no adverse effects on animal welfare and the use of GP in animal nutrition could be an alternative farm to fork strategy that would provide a considerable beneficial impact for animal breeders, consumers and the agricultural economy.

\section{Conflicts of Interest}

The Authors declare that there are no conflicts of interest.

\section{Acknowledgements}

This research project was funded by the Hellenic Agricultural Organisation DEMETER (NSRF 2007-2013). It was also funded in part by the MSc programmes Biotechnology-Nutrition \& Environment, and Toxicology of the Department of Biochemistry and Biotechnology at the University of Thessaly.

\section{References}

1 Scerra M, Caparra P, Foti F, Galofaro V, Sinatra MC and Scerra $\mathrm{V}$ : Influence of ewe feeding systems on fatty acid composition of suckling lambs. Meat Sci 76: 390-394, 2007.

2 Nieto G, Bañon S and Garrido MD: Incorporation of thyme leaves in the diet of pregnant and lactating ewes: Effect on the fatty acid profile of lamb. Small Rumin Res 105: 140-147, 2012.

3 Mapiye C, Aldai N, Turner TD, Aalhus JL, Rolland DC, Kramer JKG and Dugan MER: The labile lipid fraction of meat: From perceived disease and waste to health and opportunity. Meat Sci 92: 210-220, 2012.

4 Kotsampasi B, Christodoulou V, Zotos A, LiakopoulouKyriakides M, Goulas P, Petrotos K, Natas P and Bampidis VA: Effects of dietary pomegranate byproduct silage supplementation on performance, carcass characteristics and meat quality of growing lambs. Anim Feed Sci Technol 197: 92-102, 2014.

5 Francisco A, Dentinho MT, Alves SP, Portugal PV, Fernandes F, Sengo S, Jerónimo E, Oliveira MA, Costa P, Sequeira A, Bessa RJ and Santos-Silva J: Growth performance, carcass and meat quality of lambs supplemented with increasing levels of a tanniferous bush (Cistus ladanifer L.) and vegetable oils. Meat Sci 100: 275-82, 2015.

6 Gerasopoulos K, Stagos D, Kokkas S, Petrotos K, Kantas D, Goulas P and Kouretas D: Feed supplemented with byproducts from olive oil mill wastewater processing increases antioxidant capacity in broiler chickens. Food Chem Toxicol 82: 42-49, 2015.

7 Gerasopoulos K, Stagos D, Petrotos K, Kokkas S, Kantas D, Goulas $\mathrm{P}$ and Kouretas D: Feed supplemented with polyphenolic byproduct from olive mill wastewater processing improves the redox status in blood and tissues of piglets. Food Chem Toxicol 86: 319-327, 2015.

8 Gerasopoulos K, Stagos D, Krouezas A, Karaveli C, Barda C, Gkika H, Mitsiou D, Petrotos K, Goulas P and Kouretas D: Assessment of fatty acid allocation in plasma and tissues in piglets, using feed supplemented with byproducts from processed olive mill wastewater. In Vivo 30: 291-301, 2016.

9 Kafantaris I, Kotsampasi B, Christodoulou V, Kokka E, Kouka P, Terzopoulou Z, Gerasopoulos K, Stagos D, Mitsagga C, Giavasis I, Makri S, Petrotos K and Kouretas D: Grape pomace improves antioxidant capacity and fecal microflora of lambs. J Anim Physiol Anim Nutr 101(5): e108-e121, 2016.

10 Makri S, Kafantaris I, Stagos D, Chamokeridou T, Petrotos K, Gerasopoulos K, Mpesios A, Goutzourelas N, Kokkas S, Goulas P, Komiotis D and Kouretas D: Novel feed including bioactive compounds from winery wastes improved broilers' redox status in blood and tissues of vital organs. Food Chem Toxicol 102: 24-31, 2017.

11 Kerasioti E, Terzopoulou Z, Komini O, Kafantaris I, Makri S, Stagos D, Gerasopoulos K, Anisimov NY, Tsatsakis AM and Kouretas D: Tissue-specific effects of feeds supplemented with grape pomace or olive oil mill wastewater on detoxification enzymes in sheep. Toxicol Reports 4: 364-372, 2017. 
12 Papadopoulou A, Petrotos K, Stagos D, Gerasopoulos K, Maimaris A, Makris H, Kafantaris I, Makri S, Kerasioti E, Halabalaki M, Brieudes V, Ntasi G, Kokkas S, Tzimas P, Goulas P, Zakharenko A, Golokhvast K, Tsatsakis A and Kouretas D: Enhancement of antioxidant mechanisms and reduction of oxidative stress in chickens after the administration of drinking water enriched with polyphenolic powder from olive mill wastewaters. Oxid Med Cell Longev 2017: 8273160, 2017.

13 Kafantaris I, Stagos D, Kotsampasi B, Hatzis A, Kypriotakis A, Gerasopoulos K, Makri S, Goutzourelas N, Mitsagga C, Giavasis I, Petrotos K, Kokkas S, Goulas P, Christodoulou V and Kouretas D: Grape pomace improves performance, antioxidant status, fecal microbiota and meat quality of piglets. Animal 12(2): 246-255, 2018.

14 Botella C, de Ory I, Webb C, Cantero D and Blandino A: Hydrolytic enzyme production by Aspergillus awamori on grape pomace. Biochem Eng J 26: 100-106, 2005.

15 Deng Q, Penner MH and Zhao Y: Chemical composition of dietary fiber and polyphenols of five different varieties of wine grape pomace skins. Food Res Int 44: 2712-2720, 2011.

16 Darra NE, Tannous J, Mouncef PB, Palge J, Yaghi J, Vorobiev E, Louka $\mathrm{N}$ and Maroun RG: A Comparative study on antiradical and antimicrobial properties of red grape extracts obtained from different Vitis vinifera varieties. Food Nutr Sci 3: 1420-1432, 2012.

17 Guerra-Rivas G, Vieira C, Rubio B, Martínez B, Gallardo B, Mantecón AR, Lavín P and Manso T: Effects of grape pomace in growing lamb diets compared with vitamin $\mathrm{E}$ and grape seed extract on meat shelf life. Meat Sci 116: 221-229, 2016.

18 Wall R, Ross RP, Fitzgerald GF and Stanton C: Fatty acids from fish: the anti-inflammatory potential of long-chain omega- 3 fatty acids. Nutr Rev 68: 280-289, 2010.

19 De Caterina R: n-3 fatty acids in cardiovascular disease. N Engl J Med 364: 2439-2450, 2011

20 Jayathilake AG, Senior PV and Su XQ: Krill oil extract suppresses cell growth and induces apoptosis of human colorectal cancer cells. BMC Complement Altern Med 16: 328338,2016

21 National Research Council: Nutrient Requirements of Sheep. Washington DC: The National Academies Press, 1985.

22 Association of Official Analytical Chemists: Official Methods of Analysis of the Association of Official Analytical Chemists. Arlington VA, USA: The Association of Official Analytical Chemists, 1990.

23 Van Es AJH: Feed evaluation for ruminants. I. The systems in use from May 1977 onwards in the Netherlands. Livest Prod Sci 5: 331-345, 1978.

24 National Research Council: Guide for the Care and Use of Laboratory Animals. Washington DC: The National Academies Press, 2011.

25 European Economic Community: Council Regulation (EEC) No 2137/1992 of 23 July 1992 concerning the Community scale for the classification of carcasses of ovine animals and determining the Community standard quality of fresh or chilled sheep carcasses and extending Regulation (EEC) No 338/1991. Off J Eur Union L 214: 1-5, 1992.
26 Christodoulou V, Bampidis VA, Sossidou E and Ambrosiadis J: Evaluation of Florina (Pelagonia) sheep breed for growth and carcass traits. Small Rumin Res 70: 239-247, 2007.

27 Yuan SB, Chen DW, Zhang KY and Yu B: Effects of oxidative stress on growth performance, nutrient digestibilities and activities of antioxidative enzymes of weanling pigs. AsianAustralas J Anim Sci 20: 1600-1605, 2007.

28 Payne RL and Southern LL: Changes in glutathione peroxidase and tissue selenium concentrations of broilers after consuming a diet adequate in selenium. Poult Sci 84: 1268-1276, 2005.

29 Montagne L, Pluske JR and Hampson DJ: A review of interactions between dietary fibre and the intestinal mucosa, and their consequences on digestive health in young non-ruminant animals. Anim Feed Sci Technol 108: 95-117, 2003.

30 Chamorro S, Viveros A, Centeno C, Romero C, Arija I and Brenes A: Effects of dietary grape seed extract on growth performance, amino acid digestibility and plasma lipids and mineral content in broiler chicks. Animal 7: 555-561, 2013.

31 Iqbal Z, Ali R, Sultan JI, Ali A, Kamran Z, Khan SA and Ahsan $\mathrm{U}$ : Impact of replacing grape polyphenol with vitamin $\mathrm{E}$ on growth performance, relative organs weight and antioxidant status of broilers. J Anim Plant Sci 24: 1579-1583, 2014.

32 Wood D, Enser M, Fisher AV, Nute GR, Sheard PR, Richardson RI, Hughes SI and Whittington FM: Fat deposition, fatty acid composition and meat quality: a review. Meat Sci 78: 343-358, 2008.

33 Naht-Dinh TT: Lipid and cholesterol composition of the longissimus muscle from Angus, Brahman and Romosinuano. Thesis M.S. Texas Tech University, Lubbock, Texas, USA, 2006.

34 Simopoulos AP: Evolutionary aspects of the dietary omega-6: omega-3 fatty acid ratio: medical implications. World Rev Nutr Diet 100: 1-21, 2009.

35 Mita T, Watada H, Ogihara T, Nomiyama T, Ogawa O, Kinoshita J, Shimizu T, Hirose T, Tanaka Y and Kawamori R: Eicosapentaenoic acid reduces the progression of carotid intimamedia thickness in patients with type 2 diabetes. Atherosclerosis 191: 162-167, 2007.

36 Wood JD, Richardson RI, Nute GR, Fisher AV, Campo MM, Kasapidou E, Sheard PR and Enser M: Effects of fatty acids on meat quality: a review. Meat Sci 66: 21-32, 2003.

37 Hoenselaar R: Saturated fat and cardiovascular disease: The discrepancy between the scientific literature and dietary advice. Nutrition 28: 118-123, 2012.

38 Muíño I, Apeleo E, de la Fuente J, Pérez-Santaescolástica C, Rivas-Cañedo A, Pérez C, Díaz MT, Cañeque V and Lauzurica $S$ : Effect of dietary supplementation with red wine extract or vitamin $\mathrm{E}$, in combination with linseed and fish oil, on lamb meat quality. Meat Sci 98: 116-123, 2014. 